\title{
Secreted Semaphorins Modulate Synaptic Transmission in the Adult Hippocampus
}

\author{
Amar Sahay, ${ }^{1,4 \star}$ Chong-Hyun Kim, ${ }^{1,3 \star}$ Jehuda P. Sepkuty, ${ }^{2}$ Edward Cho, ${ }^{2}$ Richard L. Huganir, ${ }^{1,3}$ David D. Ginty, ${ }^{1,3}$ and \\ Alex L. Kolodkin ${ }^{1}$ \\ Departments of ${ }^{1}$ Neuroscience and ${ }^{2}$ Neurology and ${ }^{3}$ Howard Hughes Medical Institute, Johns Hopkins University School of Medicine, Baltimore, Maryland \\ 21205
}

\begin{abstract}
Modulation of synaptic activity is critical for neural circuit function and behavior. The semaphorins are a large, phylogenetically conserved protein family with important roles in neural development. However, semaphorin function in the adult brain has yet to be determined. Here, we show that the coreceptors for secreted semaphorins, the neuropilins, are found at synapses and localize to molecular layers of the adult mouse hippocampus and accessory olfactory cortex. Moreover, application of the secreted semaphorin Sema3F to acute hippocampal slices modulates both the frequency and amplitude of miniature EPSCs in granule cells of the dentate gyrus and pyramidal neurons of CA1. Finally, we show that mice lacking Sema3F are prone to seizures. These results suggest a novel role for semaphorins as synaptic modulators and illustrate the diverse repertoire of these guidance cues in both the formation and function of neural circuits.
\end{abstract}

Key words: semaphorins; synaptic plasticity; neuropilins; hippocampus; AMPA receptors; seizures

\section{Introduction}

The ability of the brain to encode experience is a reflection of remarkable synaptic plasticity. The identification of molecular mechanisms underlying synaptic plasticity is of tremendous importance to our understanding of how synapses store information. The semaphorins are a large, phylogenetically conserved protein family with important roles in axon guidance, dendritic branching, and cell migration (Marin et al., 2001; de Wit and Verhaagen, 2003). Unlike their roles in neural development, a function for semaphorins in the adult brain is unknown. Class 3 semaphorins (Semas) are secreted proteins and include six family members, Sema3A-Sema3F. In the nervous system, they signal through receptor complexes that contain a ligand binding subunit and a signal transducing component encoded by the neuropilin (Npn) and plexin gene families, respectively (Raper, 2000). In situ hybridization analyses show that secreted semaphorins and neuropilins are expressed in a variety of distinct cell types in the adult hippocampus. RNA transcripts for specific class 3 semaphorins are found in granule cells of the dentate gyrus (DG)

\footnotetext{
Received Dec. 23, 2004; revised Feb. 21, 2005; accepted Feb. 22, 2005.

This work was supported by The Robert Packard Center for Amyotrophic Lateral Sclerosis Research at Johns Hopkins University, National Institutes of Health/National Institute of Mental Health Grant R01MH59199, and the Howard Hughes Medical Institute. We thank D. E. Bergles, D. J. Linden, and members of the Ginty and Kolodkin laboratories for comments on this manuscript. We thank Rita Sattler and Garreth Thomas for assistance with subcellular fractionation experiments and Gera Neufeld for the sema3F-expressing cell line.

${ }^{*}$ A.S. and C.-H.K. contributed equally to this work.

Correspondence should be addressed to either David D. Ginty or Alex L. Kolodkin, Department of Neuroscience, Johns Hopkins University School of Medicine, 725 North Wolfe Street, Baltimore, Maryland 21205. E-mail: dginty@jhmi.edu or kolodkin@jhmi.edu.

A. Sahay's present address: Columbia University, College of Physicians and Surgeons, Center for Neurobiology and Behavior, 1051 Riverside Drive, Box 87, Psychiatric Institute Annex, Room 767B, New York, NY 10032.

D0I:10.1523/JNEUROSC1.5255-04.2005

Copyright $\odot 2005$ Society for Neuroscience $\quad$ 0270-6474/05/253613-08\$15.00/0
}

(sema3F, sema3C, and sema3E) (Hirsch et al., 1999; Holtmaat et al., 2002; Barnes et al., 2003), hilar mossy cells (sema3E) (Miyazaki et al., 1999; Gong et al., 2003), pyramidal neurons of CA3 and CA1 (sema3F, sema3C, and sema3E) (Holtmaat et al., 2002; Barnes et al., 2003; Gong et al., 2003), cell bodies of hippocampal afferents in the entorhinal cortex (sema3A) (Giger et al., 1998a), and interneurons (sema3F and sema3C) (Bagri et al., 2003; Gong et al., 2003) (data not shown). High levels of $n p n-1$ and $n p n-2$ transcripts are detected in dentate granule cells and CA3 pyramidal neurons, and lower levels are found in CA1 pyramidal neurons (Giger et al., 2000; Holtmaat et al., 2003). npn-2 transcripts are also abundant in hilar mossy cells (Giger et al., 2000). In vitro and in vivo studies define selective ligand-receptor relationships between individual class 3 secreted Semas and Npns, including functional relationships between Sema3F and Npn-2, and Sema3A and Npn-1 (Pasterkamp and Kolodkin, 2003).

In addition to being spatially restricted, secreted semaphorin and neuropilin expression is sensitive to electrical activity and experience. Expression of sema3F, sema $3 A$, and sema 3 C is decreased in rat models for temporal lobe epilepsy and kainate acidinduced status epilepticus (Barnes et al., 2003; Holtmaat et al., 2003). npn expression in the hippocampus also changes after chronic NMDA receptor blockade and kindling in rats (Shimakawa et al., 2002; O'Donnell et al., 2003). More recently, it was shown that neuropilin expression in the adult mouse hippocampus significantly increases after housing in an enriched environment or spatial learning (Cao et al., 2004). Together, these observations suggest that secreted semaphorins may play a role in the regulation of synaptic transmission.

Here, we address the function of secreted semaphorins in the adult brain. We show that neuropilins are found at synapses and 
localize to distinct molecular layers of the adult mouse hippocampus and accessory olfactory cortex (AOC). In acute hippocampal slices, we demonstrate that recombinant Sema3F can modulate fast excitatory synaptic transmission by increasing both the frequency and amplitude of AMPA receptor-mediated miniature EPSC (mEPSCs) in both granule cells of the dentate gyrus and pyramidal neurons of CA1. Analysis of paired-pulse facilitation (PPF) in the CA1 region indicates that the frequency of neurotransmitter release is not regulated by Sema3F. These results suggest that the effects of Sema3F are mediated through postsynaptic mechanisms. Finally, we show that Sema3F null mice are prone to seizures, suggesting underlying Sema3Fdependent deficits in neural circuit formation and/or synaptic transmission in these mutants. These results identify a novel biological function for secreted semaphorins and suggest physiological roles for these cues in normal and pathological synaptic function.

\section{Materials and Methods}

Subcellular fractionation and postsynaptic density preparation. Subcellular membrane and cytosolic fractions and detergent extracted postsynaptic density (PSD) fractions were prepared as described previously (Cho et al., 1992), and protein concentrations were determined using a BCA reagent assay (Pierce, Rockford, IL). Each fraction was normalized to give $0.5 \mathrm{mg} / \mathrm{ml}$ final protein concentration and was then denatured by the addition of Laemmeli's sample buffer and boiled before SDS-PAGE. Western blot analyses were performed on $15 \mu \mathrm{g}$ of each fraction using the indicated antibodies: anti-PSD-95 (mouse monoclonal, 1:2000; Upstate Biotechnology, Lake Placid, NY), anti-glutamate receptor 2 (GluR2) (mouse monoclonal, 1:500; Chemicon, Temecula, CA), antisynaptophysin (mouse monoclonal, 1:2000; Sigma, St. Louis, MO), antiNpn-1 [rabbit polyclonal (Kolodkin et al., 1997)], and anti-Npn-2 [rabbit polyclonal (Giger et al., 1998b)].

Recombinant ligand preparation and characterization. HEK293 E cells were transfected with either human alkaline phosphatase (AP)-Sema3F or AP and supernatant containing $5 \%$ fetal calf serum was collected, concentrated 10-fold, and assayed for AP activity to determine ligand concentration. Sema3F-myc was purified as described by Kessler et al. (2004) with minor modifications. Ligand bioactivity was assessed in superior cervical ganglion growth cone collapse assays.

AP-fusion protein binding to tissue sections. AP-Sema3F and APSema3A binding to tissue sections was performed as described previously (Sahay et al., 2003). AP-Sema3F at $1 \mathrm{~nm}$ was used in experiments shown in Figure $1, A-D$ and $I$. AP-Sema3A at $2 \mathrm{~nm}$ was used in experiments shown in Figure $1 E-H$. In all ligand binding experiments, ligand incubations were performed for $1 \mathrm{~h}$ at room temperature.

Hippocampal slice physiology. The procedure of mEPSC recording is as follows: 6- to 9-week-old rats or mice were anesthetized and decapitated. The hippocampal region was quickly dissected out in cold artificial CSF (ASCF), and slices (350-400 $\mu \mathrm{m}$ thickness) were collected using a vibratome and were kept submerged in an oxygenated $\left(5 \% \mathrm{CO}_{2}\right.$ and $95 \% \mathrm{O}_{2}$ ) ACSF chamber for at least $2 \mathrm{~h}$. The AP-Sema3F or AP ligand concentration in storage ACSF was five times higher than those used during recordings. For recordings, each slice was transferred to the recording chamber that contained 0.3 or 1-2 nm ligand with final $1-2 \%$ serum concentration and was further preincubated for $30 \mathrm{~min}$ before starting patch-clamp recording. Cells were identified by infrareddifferential interference contrast microscopy. Patched cells were held at $-68 \mathrm{mV}$, and $500 \mathrm{~ms}$ traces were collected at $3 \mathrm{~s}$ intervals. The input resistance values of neurons were $100-350 \mathrm{M} \Omega$ for CA1 pyramidal neurons and 150-500 $\mathrm{M} \Omega$ for DG granule cells. The series resistances was maintained at 8-13 $\mathrm{M} \Omega$ for CA1 pyramidal neurons and $16-25 \mathrm{M} \Omega$ for DG granule cells. Less than $15 \%$ change of series resistance was accepted during recording. Data traces were filtered at $2 \mathrm{kHz}$. Two independent data sets were collected alternatively from each cell, and $\sim 200$ data traces per cell were analyzed together. $n$ indicates the cell number. Recordings were done at $35^{\circ} \mathrm{C}$. mEPSC was pharmacologically isolated by blocking
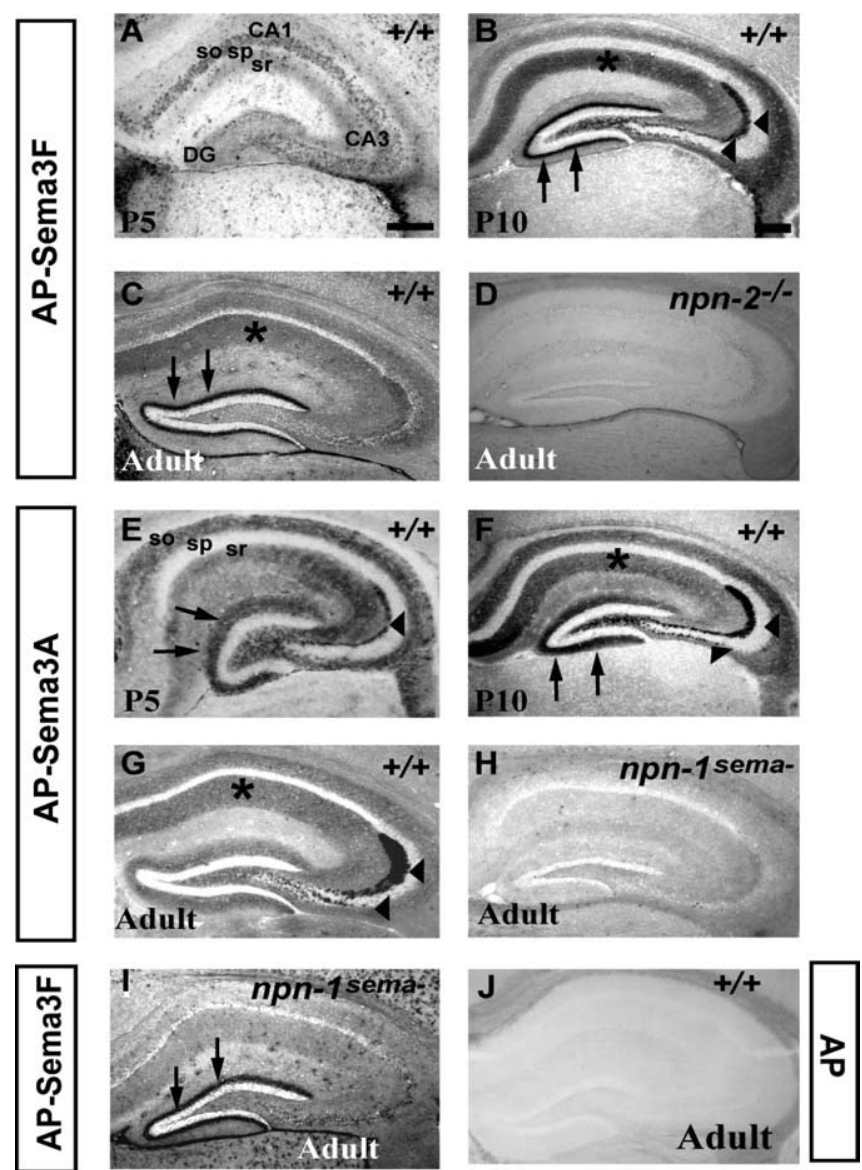

Figure 1. Npn-1 and Npn-2 localize to molecular layers of the postnatal hippocampus. $\boldsymbol{A}-\boldsymbol{C}$, AP-Sema3F (1 nm) binding to hippocampus of P5 (A), P10 (B), and adult ( $\boldsymbol{C}$ ) wild-type mice. At $P 5$, sparse binding is observed in stratum oriens (so) and stratum radiatum (sr) of CA3 and CA1. At P10, there is robust labeling of dendritic fields of CA1 and CA3 (asterisk) and the inner molecular layer of the dentate gyrus (arrows). Intense labeling of MF and IPT axons and terminals is also seen (arrowheads). Binding to the MF and IPT axons and terminals and CA dendritic fields diminishes in the adult (compare $\boldsymbol{B}, \boldsymbol{C}$ ), whereas robust binding to the iml persists. $\boldsymbol{D}$, AP-Sema3F (1 nm) binding to the hippocampus of an adult npn- $2^{-/-}$mouse. AP-Sema3F binding to the iml is not observed, suggesting that the binding observed in $\boldsymbol{B}$ and $\boldsymbol{C}$ reflects Npn-2 localization. $\boldsymbol{E}-\boldsymbol{G}$, AP-Sema3A ( 2 nM) binding to the hippocampus of P5 (E), P10 (F), and adult $(\boldsymbol{G})$ wild-type mice. $\boldsymbol{E}$, At P5, AP-Sema3A binds to stratum oriens and stratum radiatum of CA1 and CA 3 and molecular layers of the dentate gyrus (arrows) and MF axons (arrowheads). $\boldsymbol{F}$, At P10, striking labeling of dendritic fields of CA1 and CA3 (asterisk), MF and IPT axons and terminals (arrowheads), and the outer and inner molecular layer of the dentate gyrus (arrows) is seen. $\mathbf{G}$, In the adult hippocampus, robust AP-Sema3A binding to MF and IPT axons and terminals persists, and weaker binding to $C$ A-dendritic fields is observed. $\boldsymbol{H}, A P$-Sema 3 A binding to the hippocampus of an adult $n p n-1^{\text {sema- }}$ mouse. AP-Sema3A binding to MF or IPT is not detected, suggesting that the binding observed in $\boldsymbol{E}-\boldsymbol{G}$ is reflective of Npn-1 localization. $\boldsymbol{I}$, AP-Sema3F ( $1 \mathrm{~nm})$ binding to the iml in hippocampus of adult $n p n-1^{\text {sema- }}$ mice is similar to that observed in wild-type mice (arrows, compare I, C. J, AP binding to adult wild-type brain section. No binding of $2 \mathrm{~nm}$ ( $6 \mathrm{~nm}$ not shown) AP control ligand is observed. sp, Stratum pyramidale. Scale bars: (in $\boldsymbol{A}) \boldsymbol{A}, \boldsymbol{E}, 150 \mu \mathrm{m}$; (in $\boldsymbol{B}) \boldsymbol{B}-\boldsymbol{D}, \boldsymbol{F}-\boldsymbol{I}, 100 \mu \mathrm{m}$; (in $\boldsymbol{B}) \boldsymbol{J}, 100 \mu \mathrm{m}$.

NMDA receptor- and $\mathrm{GABA}_{\mathrm{A}}$-mediated transmission and $\mathrm{Na}^{+}$voltagegated currents (in mM: $0.1 \mathrm{APV}, 0.1$ picrotoxin, 0.001 bicuculline, and 0.001 TTX) in ACSF (in mm: $12 \mathrm{NaCl}, 5 \mathrm{KCl}, 26 \mathrm{NaHCO}_{3}, 1.25$ $\mathrm{NaH}_{2} \mathrm{PO}_{4} \mathrm{H}_{2} \mathrm{O}, 3 \mathrm{CaCl}_{2}$, and $1.5 \mathrm{MgSO}_{4}$ ). Compositions of intracellular solution are as follows (in mM): 135 cesium methanesulfonate, 0.5 EGTA, 10 HEPES, $8 \mathrm{NaCl}$, 2 ATP, $0.3 \mathrm{GTP}$, and 5 [ $N$-(2,6-dimethylphenyl carbamoylmethyl)triethylammonium bromide] (QX-314). The data were analyzed using a Minianalysis program (version 6.0; Synaptosoft, Decatur, GA) and shown as mean $\pm \mathrm{SE}$.

The field EPSP (fEPSP) input-output curve was measured at six stimulation current intensities for each slice through metal bipolar electrodes. 
BAOT
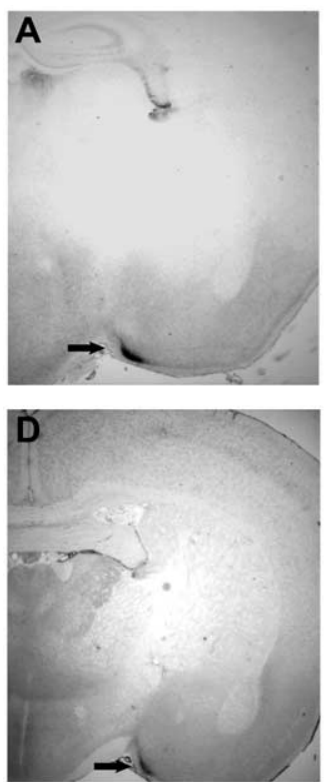

MEA
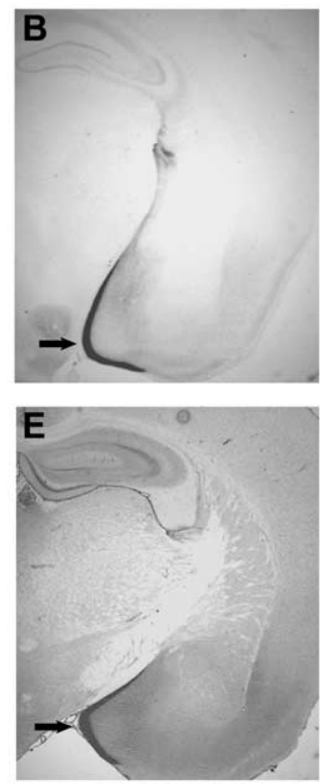

PMCO
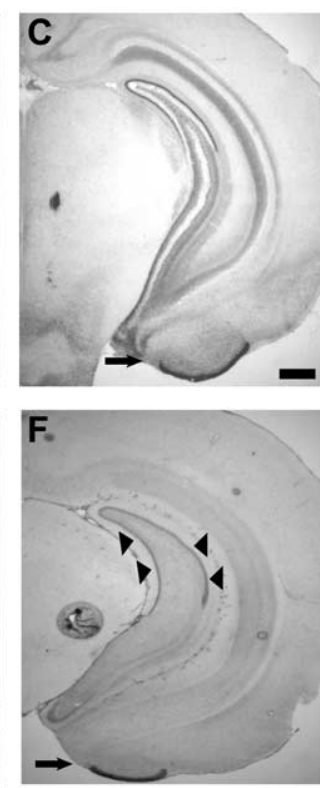

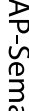

Adult

Figure 2. AP-Sema3F binding to molecular layers of postnatal AOC. A-C, AP-Sema3F (1 nM) binding to the AOC at P10. AP-Sema3F binds robustly to distinct regions of the accessory olfactory cortex: the BAOT (arrow), bed nucleus of stria terminalis (data not shown), the MEA (arrow), and the PMCO (arrow).D-F,AP-Sema3F ( $1 \mathrm{~nm}$ ) binding to AOC in adult mice. Intenselabeling of molecular layers of BAOT, MEA, and PMCO persists in adulthood (arrows in $\boldsymbol{D}-\boldsymbol{F}$ ). AP-Sema3F binding to the AOC is completely lost in brain sections of $n p n-2^{-/-}$mice (data not shown). Arrowheads in $F$ indicate AP-Sema3F binding to the iml. Scale bar, $25 \mu \mathrm{m}$.

with gaseous isofluorane when necessary. After shaving and cleansing the surgical site with $2 \%$ benzalkonium $\mathrm{HCl}$, a $1 \mathrm{~cm}$ longitudinal incision was made on the scalp. The periostium was carefully peeled away from the skull. Two machine screws (stainless steel flat head 1/16 inch, part MX-000120-1F; Small Parts, Miami Lakes, FL) were attached to the skull, $\sim 2 \mathrm{~mm}$ anterior to the bregma and $2 \mathrm{~mm}$ on either side of the sagittal suture. One screw was attached $\sim 6-8$ $\mathrm{mm}$ anterior to the bregma and $2 \mathrm{~mm}$ on one side of the sagittal suture. A tripolar electrode unit (part MS333; Plastics One, Roanoke, VA) was cut such that each wire was $\sim 1 \mathrm{~cm}$ long. The end of each electrode wire was looped around the screw with a dab of liquid colloidal silver (product \#16034; Ted Pella, Redding, CA) and secured with glue (Loctite 411; Loctite, Rocky Hill, CT). The entire electrode unit was secured on the head with cranioplastic cement (parts \#300CCP and \#300CCL; Plastics One) After a $24 \mathrm{~h}$ recovery period, mice were placed daily in the EEG recording chamber, allowing unrestrained movement while recording. Signals were recorded using Grass Instruments (Quincy, MA) EEG machine model 8-16 with the bandpass filters of the amplifiers set between 1 and $70 \mathrm{~Hz}$. Sensitivity was set to 7 $\mu \mathrm{V} / \mathrm{mm}$ and paper speed to $30 \mathrm{~cm} / \mathrm{s}$. EEG was recorded for $20 \mathrm{~min}$ or until seizure activity occurred. If seizure activity occurred, observation was continued until 5 min of non-epileptiform EEG activity had been recorded. Seven to nine recording sessions between day 2 and day 10 were performed on each animal. Clinical behavior was monitored during the EEG recording. EEG recording and interpretation was performed blind with respect to genotype. Twenty minutes of each animal's recordings were analyzed. Results, expressed in spikes per minute of recording, were calculated as the average of all consecutive measurements. Total EEG time analyzed per animal was $\sim 160 \mathrm{~min}$. Average stationary time was $44.06 \mathrm{~min}\left(\mathrm{semajF}^{-/-}\right)$and $33.02 \mathrm{~min}$ (wildtype littermates). Average exploratory recording time was $115.93 \mathrm{~min}$ (sema3 $F^{-1-}$ ) and 126.97 min (wild-type littermates). All animal procedures were approved by the animal care and use committee of the Johns Hopkins University School of Medicine.

\section{Synaptophysin}

PSD-95
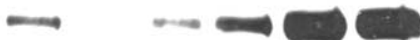

GluR2

Figure 3. Npn-1 and Npn-2 are enriched in synaptosomal and postsynaptic density fractions, respectively. Subcellular fractions of adult rat forebrain were generated with progressive enrichment for synaptic membranes as verified by immunoblotting fractions for synaptophysin, PSD-95, and GluR2 (AMPA receptor subunit localized to synaptic membranes). Npn-1 is enriched in the synaptosomal membrane fraction and is present in PSD-I and PSD-II fractions. Neuropilin-2 is present in the synaptosomal fraction and is highly enriched to a similar extent as GluR2 in PSD-I and PSD-II fractions.

As a presynaptic input parameter, fiber volley amplitude was measured. As a postsynaptic response parameter, the slope of early fEPSP (10-90\% of peak) response was measured. Field PPF ratio (slope2/slope1) was measured at the following intervals (in msec): 30, 50, 100, 150, and 250.

EEG recordings. sema3F null and wild-type littermates were anesthetized with 2,2,2-tribromoethanol (15-20 ml/kg). This was supplemented

\section{Results}

Neuropilins are found at synapses and localize to molecular layers of the adult mouse hippocampus and accessory olfactory cortex

To address whether secreted semaphorins play a role in hippocampal synaptic transmission, we first mapped the distribution of cell surface receptors for secreted semaphorins in the postnatal mouse hippocampus. In situ hybridization analyses using Npn-specific riboprobes are informative about transcript distribution but fail to define receptor protein localization. Therefore, we performed ligand binding experiments on brain sections using AP-Sema3A (2 nM) for Npn-1 and AP-Sema3F (1 nM) for Npn-2 localization, respectively (Holtmaat et al., 2002). As controls for ligand binding specificity, we used mice lacking Npn-2 $\left(n p n-2^{-/-}\right)$and mice deficient in class 3 semaphorin binding to

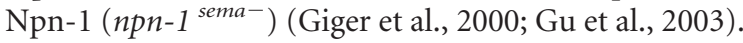

At postnatal day 5 (P5), we observe punctate AP-Sema3F binding in the stratum oriens $(\mathrm{SO})$ and stratum radiatum $(\mathrm{SR})$ of CA3 and CA1 (Fig. $1 A$ ). At P10, AP-Sema3F binds robustly to the dendritic fields of CA1 and CA3 (Fig. $1 B$, asterisk), the inner molecular layer of the dentate gyrus (iml) (Fig. $1 B$, arrows), and to mossy fiber (MF) and infrapyramidal tract (IPT) axons and 
terminals (Fig. $1 B$, arrowheads). Robust APSema3F binding to the iml along the entire length of the septotemporal axis of the hippocampus persists in the adult (Figs. $1 C$, arrows, $2 F$, arrowheads). AP-Sema3F also binds to adult CA3 and CA1 dendritic fields, albeit at lower levels than what is observed at P10 (Fig. 1, compare $B, C$ ).

In addition to the adult hippocampus, Npn-2 is also found at abundant levels in the molecular layers of the accessory olfactory cortex (Fig. 2). Robust binding of APSema3F is observed as early as P10 and throughout adulthood in the molecular layer of the bed nucleus of the accessory olfactory tract (BAOT), the medial amygdaloid nucleus (MEA), and the posteromedial cortical amygdaloid nucleus (PMCO), all of which receive synaptic input from mitral/tufted cells in the accessory olfactory bulb (von Campenhausen and Mori, 2000). We do not observe APSema3F binding to the iml of the hippocampus or molecular layer of the accessory olfactory cortex of $n p n-2^{-/-}$brain sections at the concentrations used in experiments on wild-type brain sections (1 or $2 \mathrm{~nm}$ ) (Fig. $1 \mathrm{D}$ and data not shown). Furthermore, AP-Sema3F binding to the $\mathrm{iml}$ or the accessory olfactory cortex is unaffected in brain sections of $n p n-1$ semamice (Fig. 1, compare $C, I$, arrows; and data not shown). No binding to wild-type brain sections is observed for the control AP ligand $(2 \mathrm{nM})$ (Fig. $1 \mathrm{~J})$. These results show that the AP-Sema3F binding pattern observed in wild-type brain sections reflects endogenous Npn-2 localization.

Sema3F can bind both Npn-2 and Npn-1 in vitro (Chen et al., 1998), raising the possibility that it may signal through receptor complexes containing either Npn-2 or Npn-1 in vivo. Therefore, we examined the distribution of Npn-1 in the postnatal hippocampus in situ. Because Sema3A binds Npn-1 with high affinity and does not bind Npn-2 (Chen et al., 1997), we performed AP-Sema3A section binding to localize Npn-1 in the postnatal hippocampus. At early postnatal stages, including P5, we observe patchy APSema3A binding to the SO and SR of CA 3 and CA 1 and MF axons (Fig. 1E). At P10, AP-Sema3A binds strongly to the dendritic fields of CA1 and CA3, MF and IPT axons and terminals, and both the outer and inner molecular layer of the DG (Fig. $1 F$, asterisk, arrowheads, and arrows, respectively). In the adult hippocampus, AP-Sema3A binds most robustly to MF and IPT axons and terminals (Fig. $1 G$, arrowheads). Weaker binding to CA dendritic fields persists, and binding to the molecular layers of the DG is greatly diminished (Fig. $1 G$, asterisk indicates dendritic field). AP-Sema3A fails to bind the hippocampus of $n p n-1$ semamice, suggesting that the binding pattern we observe in wild-type brain sections reflects endogenous localization of Npn-1 (Fig. $1 H$ ). Furthermore, AP-Sema3A binding to endogenous receptors is unchanged when performed in $n p n-2$ mutants (Giger et al., 2000). Together, these results show that Npn-1 and Npn-2 local-

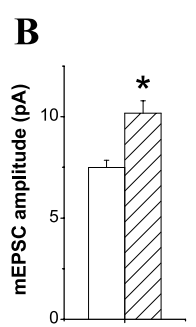

C
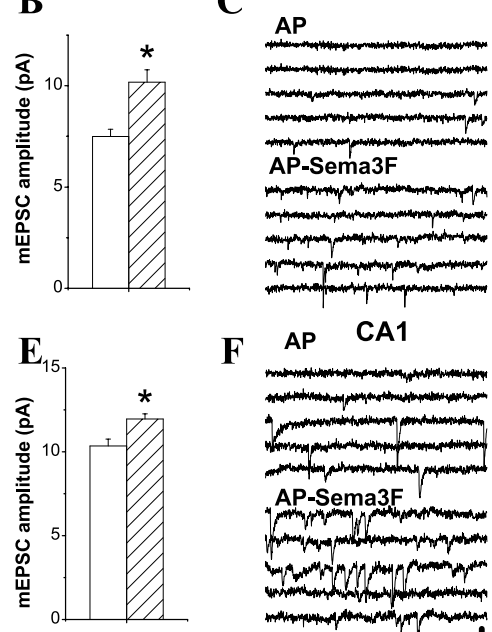

F
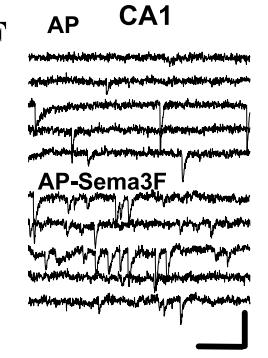

G

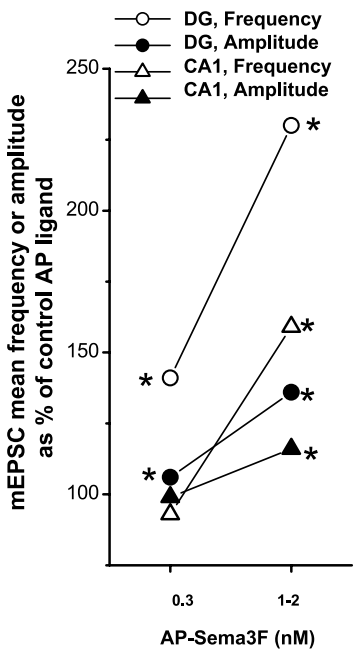

Figure 4. Sema3F can modulate synaptic transmission in rat hippocampal slices. $\boldsymbol{A}, \boldsymbol{B}, \boldsymbol{D}, \boldsymbol{E}$, Plots of effect of $A P$-Sema3F versus AP ligand (1-2nM) on the frequency $(\boldsymbol{A}, \boldsymbol{D})$ and amplitude $(\boldsymbol{B}, \boldsymbol{E})$ of mEPSCs recorded from adult wild-type rats. $\boldsymbol{A}, \boldsymbol{B}$, Data from $D G$ granule cells; $\boldsymbol{D}, \boldsymbol{E}$, data from CA1 pyramidal neurons. Open bars indicate AP ligand data, and hatched bars indicate AP-Sema3F igand data. The mEPSC frequency values for DG neurons are as follows: AP versus AP-Sema $3 F$, at $1-2 \mathrm{~nm}, 1.97 \pm 0.19 \mathrm{~Hz}, n=11$ CA1 neurons are as follows: AP versus AP-Sema3F, at $1-2 n m_{1} 4.61+0.84 \mathrm{~Hz} n=18$ versus $7.31+0.61 \mathrm{~Hz} n=29 ; p=$ 0.01122 . The mEPSC amplitude values recorded from CA1 neurons are as follows: AP versus AP-Sema3F, at 1-2 nm, $10.35 \pm 0.41$ $n=18$ versus $11.96 \pm 0.30 \mathrm{pA}, n=29 ; p=0.0025$. Asterisk indicates statistical significance using two-tailed $t$ test $(\alpha=$ on frequency and amplitude of mEPSCs recorded from granule cells in DG and pyramidal cells in CA1 region of 6- to $\mathrm{Hz}, n=21, p=4.816 \times 10^{-5}$; at $1-2 \mathrm{~nm}, 1.97 \pm 0.19 \mathrm{~Hz}, n=11$ versus $4.53 \pm 0.39 \mathrm{~Hz}, n=15 ; p=6.869 \times 10^{-7}$. Filled circles indicate the amplitude of mEPSCs recorded from DG granule cells: AP versus AP-Sema3F, at $0.3 \mathrm{~nm}, 7.83 \pm 0.18 \mathrm{pA}, n=18$ indicate the frequency of mEPSCs recorded from CA1 pyramidal neurons. AP versus AP-Sema3F, at $0.3 \mathrm{~nm}, 3.25 \pm$ $0.3 \mathrm{~nm}, 9.95 \pm 0.33 \mathrm{pA}, n=16$ versus $9.88 \pm 0.33 \mathrm{pA}, n=20, p=0.8876$; at $1-2 \mathrm{~nm}, 10.35 \pm 0.41 \mathrm{pA}, n=18$ versus $11.96 \pm$ $0.30 \mathrm{pA}, n=29, p=0.0025)$. Asterisk indicates statistical significance using two-tailed $t$ test $(\alpha=0.05)$.

ize to distinct synapse-rich molecular layers of the postnatal mouse hippocampus. In addition, high levels of Npn-2 are seen in the molecular layer of the accessory olfactory cortex.

To determine whether neuropilins are found at synapses, we examined the distribution of Npn-1 and Npn-2 in subcellular fractions generated from adult rat forebrain (Cho et al., 1992) using antibodies raised against Npn-1 and Npn-2 (Kolodkin et al., 1997; Giger et al., 1998b). Indeed, both Npn-1 and Npn-2 are found in synaptic membrane fractions (Fig. 3). Npn-1 is enriched in the synaptophysin-positive synaptosomal membrane fraction (Fig. 3), whereas Npn-2 is highly enriched to a similar extent as GluR2 in the postsynaptic density fractions (PSDI-PSDII) (Fig. 3 ). These results show that Npn-1 and Npn-2 are localized to synapses and may thus play a role in synaptic transmission.

\section{Sema3F can modulate synaptic physiology}

To directly test the hypothesis that secreted semaphorins regulate synaptic function, we asked whether Sema3F can modulate basal excitatory synaptic transmission in acute hippocampal slices. We examined the effects of bath-applied AP-Sema3F, or AP ligand as 
Table 1. Effects of 0.3 and 1-2 nM AP-Sema3F on rise time and decay time constants of mEPSCs recorded from adult rat DG granule cells and CA1 pyramidal neurons

\begin{tabular}{|c|c|c|c|c|c|c|}
\hline Rat, mEPSC properties & $\mathrm{AP}(0.3 \mathrm{~nm})$ & $\begin{array}{l}\text { AP Sema3F } \\
(0.3 \mathrm{~nm})\end{array}$ & $\begin{array}{l}p \text { values, two-tailed } \\
t \text { test; } \alpha=0.05\end{array}$ & AP $(1-2 n M)$ & $\begin{array}{l}\text { APSema3F } \\
(1-2 \text { nм) }\end{array}$ & $\begin{array}{l}p \text { values, two-tailed } \\
t \text { test; } \alpha=0.05\end{array}$ \\
\hline \multicolumn{7}{|l|}{$D G$} \\
\hline mEPSC rise ( $10-90 \%$ of peak, msec) & $1.44 \pm 0.02$ & $1.43 \pm 0.02$ & $p>0.05$ & $1.85 \pm 0.05$ & $1.59 \pm 0.04$ & $p<0.01^{*}$ \\
\hline mEPSC decay time constant (msec) & $3.88 \pm 0.06$ & $3.97 \pm 0.06$ & $p>0.05$ & $4.11 \pm 0.09$ & $3.58 \pm 0.08$ & $p<0.01^{*}$ \\
\hline \multicolumn{7}{|l|}{ CA1 } \\
\hline mEPSC rise time ( $10-90 \%$ of peak, msec) & $1.71 \pm 0.03$ & $1.75 \pm 0.03$ & $p>0.05$ & $2.11 \pm 0.04$ & $2.04 \pm 0.03$ & $p>0.05$ \\
\hline mEPSC decay time constant (msec) & $4.53 \pm 0.09$ & $4.73 \pm 0.11$ & $p>0.05$ & $5.17 \pm 0.13$ & $5.06 \pm 0.08$ & $p>0.05$ \\
\hline
\end{tabular}

${ }^{*} \alpha=0.05$, statistical significance using two-tailed $t$ test.

A

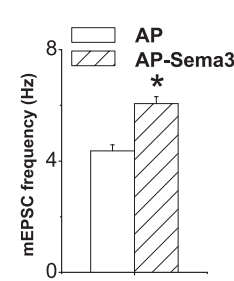

C

CA1

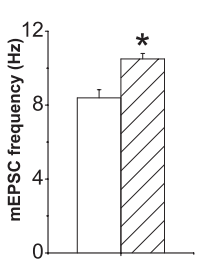

B

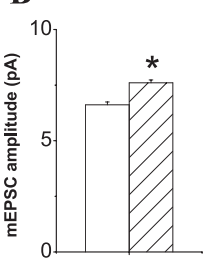

D

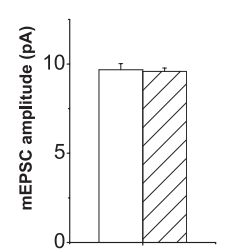

$\mathbf{E}$

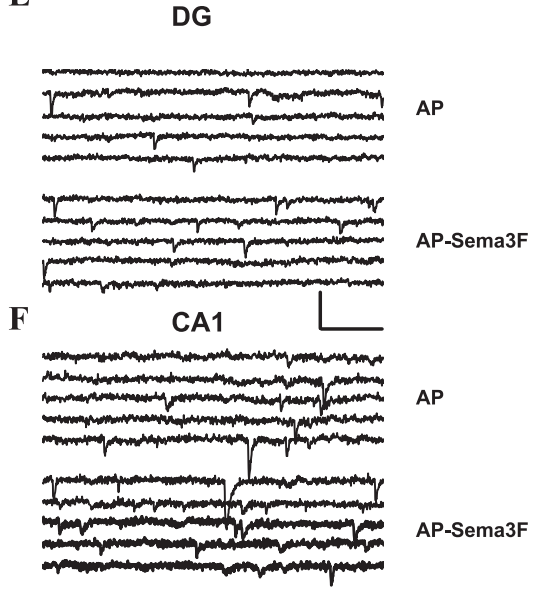

Figure 5. Sema3F can modulate synaptic transmission in mouse hippocampal slices. $\boldsymbol{A}-\boldsymbol{D}$, Plots of effect of AP-Sema3F versus AP ligand (1-2 nM) on the frequency $(\boldsymbol{A}, \boldsymbol{C})$ and amplitude $(\boldsymbol{B}, \boldsymbol{D})$ of mEPSCs recorded from adult wild-type mice. $\boldsymbol{A}, \boldsymbol{B}, \mathrm{Data}$ from DG granule cells; $C, D$, data from CA1 pyramidal neurons. Open bars indicate AP ligand data, and hatched bars indicate AP-Sema3F ligand data. The mEPSC frequency and amplitude values are as follows (AP vs AP-Sema3F): $A, 4.36 \pm 0.22 \mathrm{~Hz}, n=17$ versus $6.06 \pm 0.25 \mathrm{~Hz}, n=31, p=1.886 \times 10^{-6} ; B, 6.61 \pm 0.13 \mathrm{pA}, n=17$ versus $7.60 \pm 0.13 \mathrm{pA}, n=31, p=7.382 \times 10^{-7}$; C, $8.40 \pm 0.45 \mathrm{~Hz}, n=18$ versus $10.50 \pm 0.30 \mathrm{~Hz}, n=28, p=1.966 \times 10^{-5} ; \boldsymbol{D}, 9.68 \pm 0.34 \mathrm{pA}, n=18$ versus $9.58 \pm 0.20$ $\mathrm{pA}, n=28, p=0.7638$. Asterisk indicates statistical significance using two-tailed $t$ test $(\alpha=0.05) . \boldsymbol{E}, \boldsymbol{F}$, Example mEPSC traces from one representative mouse dentate granule cell and one CA1 pyramidal neuron in AP- or AP-Sema3F-treated mouse hippocampal slices. Calibration: $100 \mathrm{~ms}, 20 \mathrm{pA}$.

a control, on AMPA-receptor mediated mEPSCs in dentate granule cells and pyramidal neurons of CA1. We chose AP ligand as a control because it does not bind to neuropilins and is prepared and quantified under the same conditions as AP-Sema3F (see Materials and Methods). Acute hippocampal slices were preincubated with ACSF medium containing recombinant Sema3F or control ligand for $2-3 \mathrm{~h}$. We then performed whole-cell patchclamp recordings from granule cells of the dentate gyrus and pyramidal neurons of CA1 (see Materials and Methods). During recording periods, slices were continuously perfused with ACSF containing recombinant Sema3F or control ligand.

Bath-applied AP-Sema3F (1-2 nM) elicited a dramatic increase $(130 \%)$ in the average frequency of mEPSCs recorded from dentate granule cells in rat hippocampal slices compared with control AP ligand (Fig. 4A,C; Table 1). These effects were dose dependent because, at a lower concentration $(0.3 \mathrm{nM})$, we found that AP-Sema3F also increased the frequency of mEPSCs recorded from dentate granule cells (41\%) (Fig. $4 G$ ) (for rise time and decay time constants, see Table 1). In mouse hippocampal slices, AP-Sema3F also elicited a significant increase in mEPSC frequency in dentate granule cells (Fig. $5 A, E$ ) (for rise time and decay time constants, see Table 2). As an additional control for the effects of Sema3F observed in these experiments, we purified Sema3F (Sema3F-myc) to apparent homogeneity from a cell line stably transfected with Sema3F (Kessler et al., 2004) and exam- ined its effects on mEPSC frequency in dentate granule cells. In agreement with what we observe with AP-Sema3F, Sema3F-myc increased mEPSC frequency in dentate granule cells of rat hippocampal slices (55\%) (BSA vs Sema3F-myc, $2.41 \pm$ $0.19 \mathrm{~Hz}, n=14$ vs $3.94 \pm 0.21 \mathrm{~Hz}, n=11$; $p<0.05$; two-tailed $t$ test). In addition to the effects on mEPSC frequency, APSema3F also increased mEPSC amplitude in dentate granule cells of rat hippocampal slices in a dose-dependent manner (Fig. $4 B, G$; Table 1). The effects of AP-Sema3F on mEPSC amplitude in mouse hippocampal slices were less pronounced. AP-Sema3F (1-2 nM) significantly increased mEPSC amplitude recorded from DG cells compared with control ligand (Fig. 5B,E; Table 2). Together, these results show that Sema3F can modulate dentate granule cell synaptic transmission by increasing the frequency and amplitude of mEPSCs.

Next, we asked whether Sema3F has similar effects on frequency and amplitude of mEPSCs recorded from CA1 pyramidal neurons. At lower concentrations $(0.3$ nM), AP-Sema3F did not elicit a change in either amplitude or frequency of mEPSCs in CA1 pyramidal neurons of rat hippocampal slices (Fig. 4G; Table 1). However, addition of a higher concentration of AP-Sema3F (1-2 nM) significantly increased both the frequency and amplitude of mEPSCs in CA1 pyramidal neurons of rat hippocampal slices (59 and 16\%, respectively) (Fig. $4 D, E$ ). No change in rise time and decay time constants was observed (Table 1). AP-Sema3F (1-2 nM) also increased the frequency of mEPSCs in CA1 pyramidal neurons of mouse hippocampal slices (Fig. 5C,F; Table 2). No change in mEPSC amplitude was seen (Fig. 5D, F; Table 2).

The effect of Sema3F on mEPSC frequency raises the question as to whether Sema3F acts presynaptically. Therefore, we first compared the fiber volley amplitude in CA1 of AP- and APSema3F-treated rat hippocampal slices. We measured the field EPSP at six stimulation intensities. To control for the differential recruitment of presynaptic axons across slices, we plotted the synaptic responses against the presynaptic fiber volley amplitude. No significant difference in the input-output curves was observed between AP- and AP-Sema3F-treated slices (Fig. 6A). To determine whether Sema3F can alter vesicle release probability, we measured PPF in CA1 of AP- and AP-Sema3F-treated hippocampal slices (Fig. $6 B$ ). Sema3F did not significantly change $\mathrm{PPF}$ at 30,50, 100, 150, and $250 \mathrm{~ms}$ pulse intervals. These results 
Table 2. Effects of 1-2 nм AP-Sema3F on rise time and decay time constants of mEPSCs recorded from adult mouse DG granule cells and CA1 pyramidal neurons

\begin{tabular}{lll}
\hline Mouse, mEPSC properties & AP (1-2 nm) & AP-Sema3F (1-2 nm) \\
\hline DG & & $p$ values, two-tailed $t$ test; $\alpha=0.05$ \\
mEPSC rise time (10-90\% of peak, msec) & $1.78 \pm 0.03$ & $1.68 \pm 0.02$ \\
$\quad$ mEPSC decay time constant (msec) & $3.82 \pm 0.06$ & $3.66 \pm 0.03$ \\
CA1 & & $1.97 \pm 0.02$ \\
mEPSC rise time (10-90\% of peak, msec) & $1.86 \pm 0.02$ & $4.63 \pm 0.30$ \\
mEPSC decay time constant (msec) & $4.28 \pm 0.08$ & $p<0.01^{*}$ \\
\hline
\end{tabular}

${ }^{*} \alpha=0.05$, statistical significance using two-tailed $t$ test
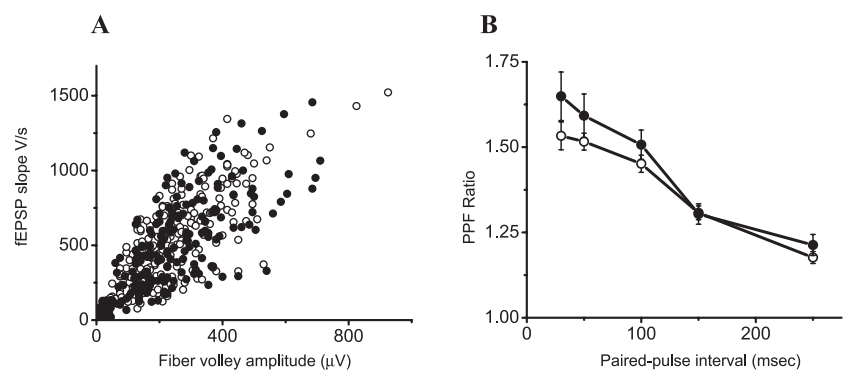

Figure 6. Effect of Sema3F on fiber volley and PPF in CA1 of rat hippocampal slices. $\boldsymbol{A}$, Normal basal synaptic transmission property measured as presynaptic input versus postsynaptic field EPSP output responses in CA1 region of rat hippocampal slices. Fiber volley amplitude and fEPSP slope represent presynaptic input strength and postsynaptic fEPSP response, respectively. Each slice was stimulated with six incremental current magnitudes. Open circles indicate the synaptic responses with $\mathrm{AP}$ ( $n=39$ slices), and filled circles indicate the synaptic responses with APSema3F ligand ( $n=38$ slices). $\boldsymbol{B}$, PPF was measured as a ratio of second fEPSP slope over the first fEPSP slope in CA1 region of rat hippocampal slices. Five different paired-pulse intervals were used (in msec): 30, 50, 100, 150, and 250. Open circles indicate PPF with AP ( $n=39$ ), and filled circles indicate PPFs with AP-Sema3F ligand $(n=34)$. There is no significant difference in PPF ratio at five different intervals.

suggest that the Sema3F effects on mEPSC frequency in CA1 are unlikely to be mediated by changes in the probability of vesicle release.

\section{Mice lacking Sema3F are prone to seizures}

Alterations in the physiological properties of specific neuronal circuits in the forebrain are often associated with epileptogenesis and/or epilepsy (Morimoto et al., 2004). To determine whether mice lacking Sema3F (sema3F ${ }^{-/-}$) (Sahay et al., 2003) are prone to seizures, we measured EEG activity in 3-month-old sema3 $F^{-1-}$ mice and wild-type littermates using scalp electrodes. EEGs were analyzed for epileptic activity while animals were awake and monitored for behavioral changes. A seizure was defined as an epileptogenic EEG change accompanied by a behavioral change from exploratory to stationary episodes (Sepkuty et al., 2002). sema3 $F^{-/-}$mice showed high-voltage spikes and runs of polyspikes indicative of epileptic activity and had a fivefold increase in spikes per minute of recording ( $4.59 \pm 0.48 \mathrm{spikes} / \mathrm{min})$ compared with wild-type littermates $(0.79 \pm 0.13$ spikes $/ \mathrm{min})(p<0.0009$; two-tailed $t$ test; $n=6$ sema $\left.3 F^{+/+} ; n=8 s e m a 3 F^{-/-}\right)$. In addition, the average duration of spike discharges was significantly higher in sema $3 F^{-1-}$ mice compared with controls during stationary episodes but was not significantly different during exploratory episodes [stationary episodes, sema $3 F^{-/-}$vs control, 12.34 vs 3.44, $p=0.01$, two-tailed $t$ test (Fig. $7 A, B)$; exploratory behavior, sema $3 F^{-1-}$ vs control, 2.08 vs $0.69, p=$ 0.06 , two-tailed $t$ test (Fig. $7 C, D)]$. Also, sema3 $F^{-1-}$ mice showed a significantly higher duration of spike discharges during stationary episodes than in exploratory episodes, in contrast to wild-type mice in which durations of spike discharges during stationary and exploratory episodes were not significantly different $\left(\mathrm{sema}_{3} \mathrm{~F}^{-/-}\right.$, average, 12.34 vs $2.09, p=0.0003$, two-tailed $t$ test; wild type, average 3.44 vs
$0.69, p=0.17$, two-tailed $t$ test). Approximately $30 \%$ of stationary episodes observed for sema $3 \mathrm{~F}^{-/-}$mice were associated with epileptogenic EEG changes, defining these behavioral events as seizures. Stationary episodes were also observed for wild-type littermates, but none of these were associated with EEG changes. In addition, behavioral monitoring also showed occasional brief body and tail jerks in sema $3 F^{-/-}$mice during stationary episodes that were absent in wildtype littermates. These experiments show that, in the absence of Sema3F, mice are prone to seizures defined as an epileptogenic EEG change accompanied by a behavioral change.

\section{Discussion}

Our studies demonstrate a new biological function for semaphorins as modulators of basal synaptic transmission in the adult hippocampus. We show that neuropilins are found in mature CNS synapses and are localized to the molecular layers of the hippocampus and accessory olfactory cortex during early postnatal life and adulthood. Previous studies mapping neuropilin distribution in the adult mouse brain have relied on in situ hybridization assays, which fail to convey the protein distribution for these receptors. Here, we used AP-tagged secreted semaphorins because these probes faithfully map the localization of Npn-1 and Npn-2 at the protein level in the adult mouse hippocampus. Although the ligand binding assay used here lacks the resolution afforded by immunostaining, it confers a high level of specificity, allowing sensitive assessment of functional secreted semaphorin binding sites in situ. Interestingly, the highest levels of Npn-1 and Npn-2 in the adult hippocampus are found in complementary components of dentate granule cell circuitry, with Npn-1 detected in MF axons and terminals and Npn-2 predominantly localized to the inner molecular layer of the DG. It is plausible that the C-terminal PDZ (PSD-95/Discs large/zona occludens-1) ligand binding motifs in Npn-1 and Npn-2 contribute to their differential targeting in synaptic sites. In addition to the hippocampus, Npn-2 is also found in the molecular layer of the accessory olfactory cortex in which mitral/tufted cell axons synapse on third-order neurons. Cell type-specific gene ablation studies will reveal the physiological requirement of synaptically localized neuropilins in these distinct neural circuits in vivo.

To begin to address the role of secreted semaphorin signaling at synapses, we asked whether Sema3F can modulate AMPA receptor-mediated currents in acute hippocampal slices. Because Sema3F is a repulsive cue for young hippocampal neurons, we chose to use rat and mouse hippocampal slices in this study, an approach that leaves the architecture of the hippocampus essentially intact and consequently allows for an assessment of how Sema3F affects CA1 and DG synaptic transmission. We find that recombinant Sema3F can modulate basal synaptic transmission by increasing the frequency and amplitude of mEPSCs in both dentate granule cells and pyramidal neurons of CA1. The effects of Sema3F on mEPSC frequency and amplitude in DG neurons are likely to be mediated by Npn-2 because AP-Sema3F does not bind the iml of $n p n-2^{-/-}$mice. AP Sema3F, however, binds to 


\section{wild-type}

A

\section{Stationary}

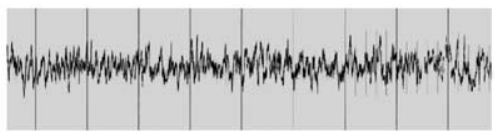

\section{Exploring}

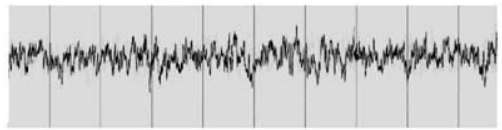

sema3F-/-

B

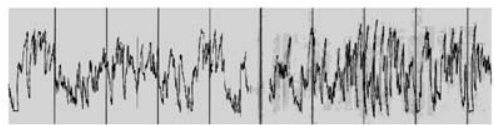

D

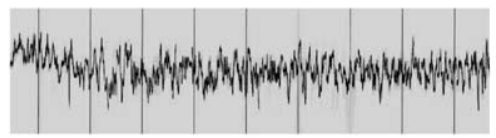
An example of a typical EEG from a sema $3 F$ null mouse while stationary, revealing high-voltage spikes and polyspike discharges for a duration of $\sim 3-5 s\left(^{*}\right)$.C, An example of a typical EEG from a wild-type mouse while exploring. A normal mixture of frequencies without spikes was seen. $\boldsymbol{D}$, An example of a typical EEG from a sema3F null littermate while exploring. A normal mixture of frequencies without spikes was seen as in $C$. The average number of stationary and exploratory episodes did not differ significantly between sema $3 \mathrm{~F}^{-1-}$ and wild-type mice: sema $3 F^{-1-}$ versus wild-type, stationary episodes expressed as average percentage of the whole recording, 27.54 versus $20.64 \%, p=0.3$, two-tailed $t$ test; exploratory episodes expressed as average percentage of the whole recording, 72.46 versus $79.36 \%, p=0.3$, two-tailed $t$ test.

CA1 of $n p n-2$ null mice at higher concentrations ( $5 \mathrm{~nm}$; data not shown), raising the possibility that it may signal independently of Npn-2. One way to address whether Npn-2 is required for the effects of Sema3F on mEPSC frequency and amplitude is to use hippocampal slices obtained from $n p n-2$ null mice. However, the interpretation of these experiments is confounded by defects in the normal development of hippocampal circuits observed in these mice (Chen et al., 2000; Giger et al., 2000). Future studies aimed at defining the contribution of individual plexin coreceptors to secreted semaphorin-Npn signaling in mature hippocampal neurons will enable us to understand the underlying basis of these effects (Rohm et al., 2000).

How do secreted semaphorins mediate their effects at the synapse? Secreted semaphorins may modulate synaptic transmission by directly acting on the vesicle release machinery, increasing synapse number or changing AMPA receptor properties. Recently, it was shown that Sema3A, like BDNF (McAllister et al., 1995), can enhance cortical dendritic branching and growth in slice cultures (Fenstermaker et al., 2004), and in vivo class 3 semaphorin-Npn-1 interactions promote basal dendritic complexity of cortical neurons (Gu et al., 2003). Therefore, secreted semaphorin-Npn signaling and BDNF-TrkB signaling may share downstream effectors that regulate synapse number in vivo. Furthermore, there is growing evidence implicating CUB (complement subcomponents C1r/C1s, Uegf, BMP-1) domain containing type- 1 transmembrane proteins such as SOL-1 (suppressor of lurcher-1) and LEV-10 (levamisole protein) in Caenorhabditis elegans in modulation of ionotropic receptor function (Gally et al., 2004; Zheng et al., 2004). The highsequence identity shared by these CUB domain proteins and Npns raises the possibility that neuropilins may also influence ionotropic receptor properties and function. Finally, downstream effectors of secreted semaphorin signaling within the growth cone, such as Cdk5 (cyclin-dependent kinase), fyn, and LIM (the three gene products Lin-1, Isl-1, and Mec-3) kinase, have been implicated in spine development, vesicle release, and synaptic plasticity (Aizawa et al., 2001; Sasaki et al., 2002; Lai and Ip, 2003; Meng et al., 2003).

To address whether alterations in vesicle release or change in synapse number may account for the effects of Sema3F on mEPSC frequency, we analyzed PPF in AP- and AP-Sema3F-treated slices. The absence of a significant difference between control and Sema3F-treated slices in these experiments suggests that the effects of Sema3F on mEPSC frequency, at least in CA1, are not likely to be mediated through presynaptic mechanisms. Whether changes in surface expression and/or function of AMPA receptors or synapse number underlie these effects of Sema3F remains to be determined.

We show here that sema3F null mice are prone to seizures. Because Sema3F has been implicated in development of mossy fiber projections and is required for migration of cortex-bound interneurons in slices in vitro, it is difficult to determine the precise basis for the observed seizures (Chen et al., 2000; Giger et al., 2000; Marin et al., 2001; Sahay et al., 2003). A conservative interpretation is that the seizures reflect deficits in neural circuit formation in these mice. It is intriguing however, that the highest levels of Npn-2 in the adult hippocampus are found in the $\mathrm{iml}$, in which mossy cells form excitatory synapses on granule cell dendrites and interneurons. There is growing evidence indicating that alterations in physiological properties of mossy cells may increase granule cell excitability (Santhakumar et al., 2001; Ratzliff et al., 2002). Moreover, the IPT defects in sema3F null, $n p n-2$ null, and plexin-A3 null mice are similar to those observed in FMR1 (fragile $\mathrm{X}$ mental retardation protein) null, creatine kinase- $B$ null, and prion null mice, all of which show altered synaptic properties or defects in synaptic plasticity (Colling et al., 1997; Cheng et al., 2001; Huber et al., 2002; Ivanco and Greenough, 2002; Jost et al., 2002; Sahay et al., 2003). Sema3F mRNA is also a target of fragile $\mathrm{X}$ mental retardation protein (FMRP), because it was identified in a screen for high-affinity interactions between mRNAs and FMRP (Darnell et al., 2001). Although the biological significance of the FMR1-sema3F interaction in the brain is yet to be addressed, it suggests that sema3F may come under activity-dependent translational control at synapses.

In conclusion, our studies define a novel role for secreted semaphorins as modulators of synaptic transmission in the adult brain. Conditional ablation of secreted semaphorins in distinct cell types of the adult mouse hippocampus will ultimately define the potential for these ligands to modulate neural circuit function and, consequently, behavior. The results presented here show the diverse functional repertoire of secreted semaphorins in synaptic transmission and nervous system development and suggest physiological roles for these cues in both the normal and pathological function of neural circuits.

\section{References}

Aizawa H, Wakatsuki S, Ishii A, Moriyama K, Sasaki Y, Ohashi K, SekineAizawa Y, Sehara-Fujisawa A, Mizuno K, Goshima Y, Yahara I (2001) Phosphorylation of cofilin by LIM-kinase is necessary for semaphorin 3Ainduced growth cone collapse. Nat Neurosci 4:367-373. 
Bagri A, Cheng HJ, Yaron A, Pleasure SJ, Tessier-Lavigne M (2003) Stereotyped pruning of long hippocampal axon branches triggered by retraction inducers of the semaphorin family. Cell 113:285-299.

Barnes G, Puranam RS, Luo Y, McNamara JO (2003) Temporal specific patterns of semaphorin gene expression in rat brain after kainic acidinduced status epilepticus. Hippocampus 13:1-20.

Cao L, Jiao X, Zuzga DS, Liu Y, Fong DM, Young D, During MJ (2004) VEGF links hippocampal activity with neurogenesis, learning and memory. Nat Genet 36:827-835.

Chen H, Chedotal A, He Z, Goodman CS, Tessier-Lavigne M (1997) Neuropilin-2, a novel member of the neuropilin family, is a high affinity receptor for the semaphorins Sema I and Sema IV but not Sema III. Neuron 19:547-559.

Chen H, He Z, Bagri A, Tessier-Lavigne M (1998) Semaphorin-neuropilin interactions underlying sympathetic axon responses to class III semaphorins. Neuron 21:1283-1290.

Chen H, Bagri A, Zupicich JA, Zou Y, Stoeckli E, Pleasure SJ, Lowenstein DH, Skarnes WC, Chedotal A, Tessier-Lavigne M (2000) Neuropilin-2 regulates the development of selective cranial and sensory nerves and hippocampal mossy fiber projections. Neuron 25:43-56.

Cheng HJ, Bagri A, Yaron A, Stein E, Pleasure SJ, Tessier-Lavigne M (2001) Plexin-A3 mediates semaphorin signaling and regulates the development of hippocampal axonal projections. Neuron 32:249-263.

Cho KO, Hunt CA, Kennedy MB (1992) The rat brain postsynaptic density fraction contains a homolog of the Drosophila discs-large tumor suppressor protein. Neuron 9:929-942.

Colling SB, Khana M, Collinge J, Jefferys JG (1997) Mossy fibre reorganization in the hippocampus of prion protein null mice. Brain Res 755:28 -35.

Darnell JC, Jensen KB, Jin P, Brown V, Warren ST, Darnell RB (2001) Fragile X mental retardation protein targets $\mathrm{G}$ quartet mRNAs important for neuronal function. Cell 107:489-499.

de Wit J, Verhaagen J (2003) Role of semaphorins in the adult nervous system. Prog Neurobiol 71:249-267.

Fenstermaker V, Chen Y, Ghosh A, Yuste R (2004) Regulation of dendritic length and branching by semaphorin 3A. J Neurobiol [Erratum (2004) 58:423] 58:403-412-423.

Gally C, Eimer S, Richmond JE, Bessereau JL (2004) A transmembrane protein required for acetylcholine receptor clustering in Caenorhabditis elegans. Nature 431:578-582.

Giger RJ, Pasterkamp RJ, Heijnen S, Holtmaat AJ, Verhaagen J (1998a) Anatomical distribution of the chemorepellent semaphorin III/collapsin-1 in the adult rat and human brain: predominant expression in structures of the olfactory-hippocampal pathway and the motor system. J Neurosci Res $52: 27-42$.

Giger RJ, Urquhart ER, Gillespie SK, Levengood DV, Ginty DD, Kolodkin AL (1998b) Neuropilin-2 is a receptor for semaphorin IV: insight into the structural basis of receptor function and specificity. Neuron 21:1079-1092.

Giger RJ, Cloutier JF, Sahay A, Prinjha RK, Levengood DV, Moore SE, Pickering S, Simmons D, Rastan S, Walsh FS, Kolodkin AL, Ginty DD, Geppert M (2000) Neuropilin-2 is required in vivo for selective axon guidance responses to secreted semaphorins. Neuron 25:29-41.

Gong S, Zheng C, Doughty ML, Losos K, Didkovsky N, Schambra UB, Nowak NJ, Joyner A, Leblanc G, Hatten ME, Heintz N (2003) A gene expression atlas of the central nervous system based on bacterial artificial chromosomes. Nature 425:917-925.

Gu C, Rodriguez ER, Reimert DV, Shu T, Fritzsch B, Richards LJ, Kolodkin AL, Ginty DD (2003) Neuropilin-1 conveys semaphorin and VEGF signaling during neural and cardiovascular development. Dev Cell 5:45-57.

Hirsch E, Hu LJ, Prigent A, Constantin B, Agid Y, Drabkin H, Roche J (1999) Distribution of semaphorin IV in adult human brain. Brain Res 823:67-79.

Holtmaat AJ, De Winter F, De Wit J, Gorter JA, da Silva FH, Verhaagen J (2002) Semaphorins: contributors to structural stability of hippocampal networks? Prog Brain Res 138:17-38.

Holtmaat AJ, Gorter JA, De Wit J, Tolner EA, Spijker S, Giger RJ, Lopes da Silva FH, Verhaagen J (2003) Transient downregulation of Sema3A mRNA in a rat model for temporal lobe epilepsy. A novel molecular event potentially contributing to mossy fiber sprouting. Exp Neurol 182:142-150.
Huber KM, Gallagher SM, Warren ST, Bear MF (2002) Altered synaptic plasticity in a mouse model of fragile X mental retardation. Proc Natl Acad Sci USA 99:7746-7750.

Ivanco TL, Greenough WT (2002) Altered mossy fiber distributions in adult Fmr1 (FVB) knockout mice. Hippocampus 12:47-54.

Jost CR, Van Der Zee CE, In't Zandt HJ, Oerlemans F, Verheij M, Streijger F, Fransen J, Heerschap A, Cools AR, Wieringa B (2002) Creatine kinase B-driven energy transfer in the brain is important for habituation and spatial learning behaviour, mossy fibre field size and determination of seizure susceptibility. Eur J Neurosci 15:1692-1706.

Kessler O, Shraga-Heled N, Lange T, Gutmann-Raviv N, Sabo E, Baruch L, Machluf M, Neufeld G (2004) Semaphorin-3F is an inhibitor of tumor angiogenesis. Cancer Res 64:1008-1015.

Kolodkin AL, Levengood DV, Rowe EG, Tai YT, Giger RJ, Ginty DD (1997) Neuropilin is a semaphorin III receptor. Cell 90:753-762.

Lai KO, Ip NY (2003) Central synapse and neuromuscular junction: same players, different roles. Trends Genet 19:395-402.

Marin O, Yaron A, Bagri A, Tessier-Lavigne M, Rubenstein JL (2001) Sorting of striatal and cortical interneurons regulated by semaphorinneuropilin interactions. Science 293:872-875.

McAllister AK, Lo DC, Katz LC (1995) Neurotrophins regulate dendritic growth in developing visual cortex. Neuron 15:791-803.

Meng Y, Zhang Y, Tregoubov V, Falls DL, Jia Z (2003) Regulation of spine morphology and synaptic function by LIMK and the actin cytoskeleton. Rev Neurosci 14:233-240.

Miyazaki N, Furuyama T, Sakai T, Fujioka S, Mori T, Ohoka Y, Takeda N, Kubo T, Inagaki S (1999) Developmental localization of semaphorin $\mathrm{H}$ messenger RNA acting as a collapsing factor on sensory axons in the mouse brain. Neuroscience 93:401-408.

Morimoto K, Fahnestock M, Racine RJ (2004) Kindling and status epilepticus models of epilepsy: rewiring the brain. Prog Neurobiol 73:1-60.

O'Donnell J, Stemmelin J, Nitta A, Brouillette J, Quirion R (2003) Gene expression profiling following chronic NMDA receptor blockadeinduced learning deficits in rats. Synapse 50:171-180.

Pasterkamp RJ, Kolodkin AL (2003) Semaphorin junction: making tracks toward neural connectivity. Curr Opin Neurobiol 13:79-89.

Raper J (2000) Semaphorins and their receptors in vertebrates and invertebrates. Curr Opin Neurobiol 10:88-94.

Ratzliff AH, Santhakumar V, Howard A, Soltesz I (2002) Mossy cells in epilepsy: rigor mortis or vigor mortis? Trends Neurosci 25:140-144.

Rohm B, Ottemeyer A, Lohrum M, Puschel AW (2000) Plexin/neuropilin complexes mediate repulsion by the axonal guidance signal semaphorin 3A. Mech Dev 93:95-104.

Sahay A, Molliver ME, Ginty DD, Kolodkin AL (2003) Semaphorin 3F is critical for development of limbic system circuitry and is required in neurons for selective CNS axon guidance events. J Neurosci 23:6671-6680.

Santhakumar V, Ratzliff AD, Jeng J, Toth Z, Soltesz I (2001) Long-term hyperexcitability in the hippocampus after experimental head trauma. Ann Neurol 50:708-717.

Sasaki Y, Cheng C, Uchida Y, Nakajima O, Ohshima T, Yagi T, Taniguchi M, Nakayama T, Kishida R, Kudo Y, Ohno S, Nakamura F, Goshima Y (2002) Fyn and Cdk5 mediate semaphorin-3A signaling, which is involved in regulation of dendrite orientation in cerebral cortex. Neuron 35:907-920.

Sepkuty JP, Cohen AS, Eccles C, Rafiq A, Behar K, Ganel R, Coulter DA, Rothstein JD (2002) A neuronal glutamate transporter contributes to neurotransmitter GABA synthesis and epilepsy. J Neurosci 22:6372-6379.

Shimakawa S, Suzuki S, Miyamoto R, Takitani K, Tanaka K, Tanabe T, Wakamiya E, Nakamura F, Kuno M, Matsuura S, Watanabe Y, Tamai H (2002) Neuropilin-2 is overexpressed in the rat brain after limbic seizures. Brain Res 956:67-73.

von Campenhausen H, Mori K (2000) Convergence of segregated pheromonal pathways from the accessory olfactory bulb to the cortex in the mouse. Eur J Neurosci 12:33-46.

Zheng Y, Mellem JE, Brockie PJ, Madsen DM, Maricq AV (2004) SOL-1 is a CUB-domain protein required for GLR-1 glutamate receptor function in C. elegans. Nature 427:451-457. 